\title{
Synthesis and Characterization of Lanthanum Zinc Aluminate.
}

\author{
G. Kalusuraman, K. Balamurugan, N. Sankara Subramanian, I. Siva
}

\begin{abstract}
Thermal barrier coating materials (TBC) are temperature resistance material which is applied to components in gas turbine or rocker engine in order to improve the life of the component. In this work, the lanthanum Zinc Aluminate are extracted in the form of powder and synthesized using the sol gel process. For sol gel process, Sample of different weight are taken and mixed with distilled water and these are prepared with a controlled stoichiometry by mixing of components. The powder which is obtained from the sol-gel process is to be characterized and the reported.
\end{abstract}

Keywords : lanthanum Zinc aluminate, TBC.

\section{INTRODUCTION}

Thermal barrier materials (TBMs) are ceramic coatings materials which are applied in the metal component used in rocket engines or gas turbine engines. These engines are used in higher temperature applications. For the betterment of the service of the component, coating is necessary for the component. Though many research works were started 50 years ago in the TBMs, still some research is going on to find the new coating materials to improve the life of the component and also the efficiency. Alejandro Hernández et al, (2009) studied start-up cycle effects on ceramic coating that were used as thermal barrier for a gas turbine bucket application. [1]. In this work, effect of the ceramic coating for the gas turbine bucket is studied using CFD software. They reported that the thermal barrier coating of 100 micro meters can reduce the temperature by $2000 \mathrm{C}$ C. L. Wang et al, (2011) conducted studies on novel structure on low thermal conductivity for TBCs [2]. They explained theextremely low thermal conductivity obtained for the TBCs.. In their work, Lanthanum Zirconate was used as TBC. Lisa Pin et al, (2011) conducted processing, repairing and cyclic oxidation behavior of sol-gel method based TBCs [3]. They explained that why the sol-gel thermal barrier coating is prepared using dip coating method. There was a possibility to reduce the crack formed while heat treatment. Y. Wang et

Revised Manuscript Received on December 30, 2019.

* Correspondence Author

G. Kalusuraman*, Faculty of Mechanical Engineering, Kalasalingam Academy of Research and Education, Krishnankoil-626 126, India, Email: kalusunrk@gmail.com

K. Balamurugan, Department of Mechanical Engineering, VFSTR (Deemed to be University), Guntur 522213,India, Emai: Kbalan2000@gmail.com

N. Sankara Subramanian, Department of Physics. Thiagarajar College of Engineering, Madurai-625015, India Email: shankersathiya@yahoo.com

I, Siva , Faculty of Mechanical Engineering, Kalasalingam Academy of Research and Education, Krishnankoil-626 126, India, Email: isiva@klu.com al, (2011) studied the influence of pores on the thermal insulation performance of TBCs which was prepared by using the atmospheric plasma spray technique. [4]. They revealed that the defects in materials show most significant role on the active thermal conductivity. Shen Wei et al, (2012) studied the defects performance on the actual thermal conductivity of TBCs [5]. They reported that it was hard to create structure property interactions in thermal barrier coating.

Lorenzo Malavasi Et al. (2003) [6] discussed about the characterization of nanocrystalline $\mathrm{La} 1-\mathrm{xNaxMnO} 3+\delta$ samples. Rodica Rogojan Et al (2011) [7] studied about $\mathrm{AlCl} 3$ as precursor; the sol-gel method consisted in the preparation of $\mathrm{AlCl} 3$ ethanolic solution. Many researchers have worked on TBCs, but still some lack of information available in thermal barrier coating powder, In this work, the lanthanum Zinc aluminate (LZA) is to be synthesized using the sol gel process. The extracted powder is to be subjected to different heat treatment temperature to characterize the powder

\section{MATERIALS AND METHODS}

\section{A. Materials used}

Author (s) can send paper in the given email address of the journal. There are two email address. It is compulsory to send paper in both email address.

\section{B. Synthesis of lanthanum Zinc aluminate.}

The beaker is first cleaned and washed with distilled water and also dried in vacuum oven. All the materials and solvents were weighed in electronic weighing balance and mixed in cleaned beaker. A $1000 \mathrm{ml}$ beaker is filled with $600 \mathrm{ml}$ of distilled water and the materials are mixed in water. The beaker is kept on magnetic stirrer and the temperature maintained on stirrer is $80^{\circ} \mathrm{C}$. It is maintained with same temperature until the solution is changed in to gel. As soon as the solution is transformed to gel, the beaker is covered with aluminum foil to avoid fumes in environment. After the solution is transformed to gel the stirrer rpm must be kept at zero so that on further heating the gel transforms to bulk powder. The powder is obtained and let to dry. The dried powder is taken in a mortar and is grinded carefully. After extracting the powder, the powders are sintered at $450^{\circ} \mathrm{C}$ and $750^{\circ} \mathrm{C}$ for four hours 


\section{Synthesis and Characterization of Lanthanum Zinc Aluminate.}

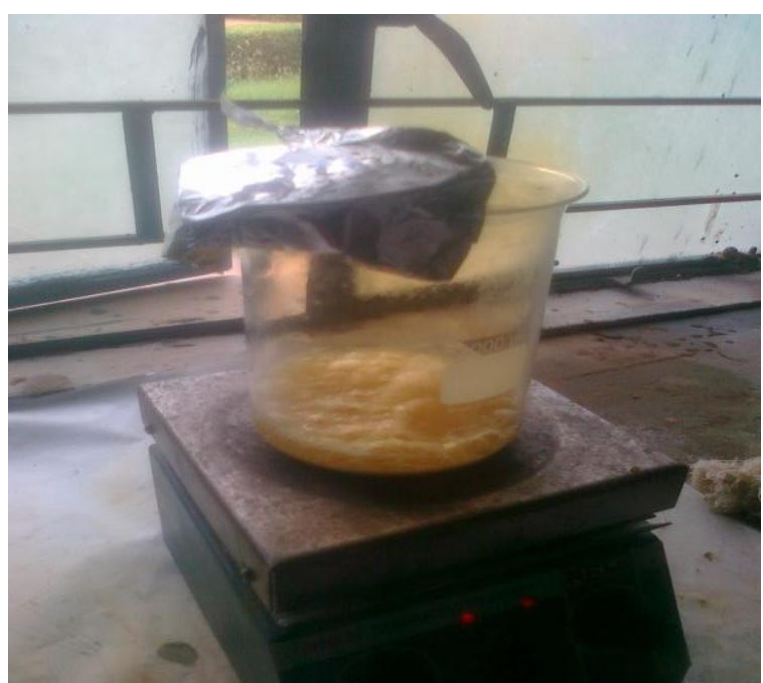

Fig. 1.Transformation Of Solution To Gel

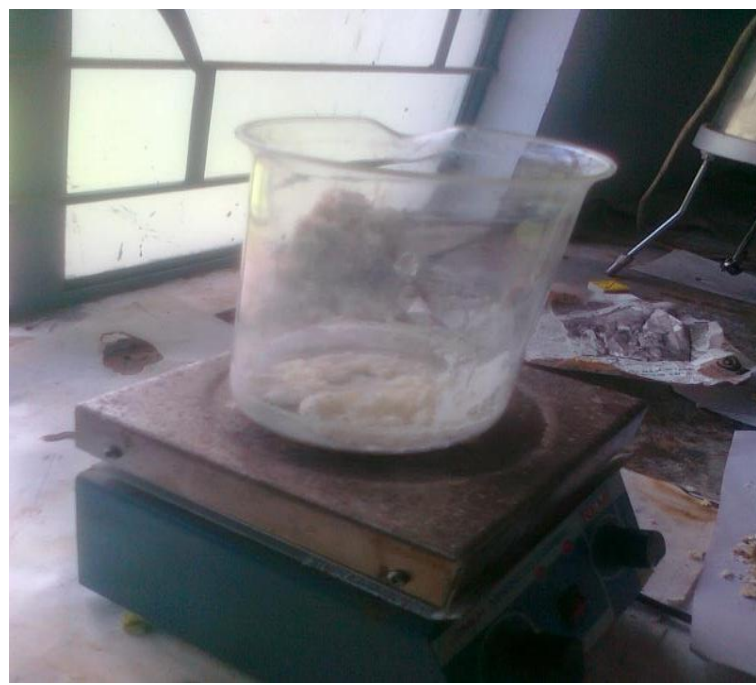

Fig 2.Powder Formation

\section{RESULTS AND DISCUSSION}

This The XRD pattern for lanthanum zinc aluminate are shown in Fig 3 and 2 for having powder annealed 4500C and $7500 \mathrm{C}$ respectively. The magnetic plumbite structure is mentioned in the XRD for having peaks at $2 \theta=320$. The other kind of characteristic were observed at $2 \theta=28^{\circ}$ and $2 \theta=32^{\circ}$ for the annealed powder at $450^{\circ} \mathrm{C}$ and also $2 \theta=30^{\circ}$ for annealed powder at $750^{\circ} \mathrm{C}$

It was observed that the widening of peak (larger half width full maximum) ensured the nono- scale average size of the particle. The maximum intensity and sharpness of peak was found powder annealed at $750^{\circ} \mathrm{C}$

The size of the particle is calculated by using the debye scherrer's formula from the XRD data

Mean grain Size $=\frac{0.91 \lambda}{\rho \cos \theta}$

Where $\lambda=1.54060 \mathrm{~A}$,

$\beta=\mathrm{B}-\mathrm{b}$;

$\beta$ is the width (observed) of the peak at an angle $2 \theta$, a half the maximum intensity, (half width full maximum), and $b$ is the effect of the instrument as determined from the nano crystalline diffraction line.

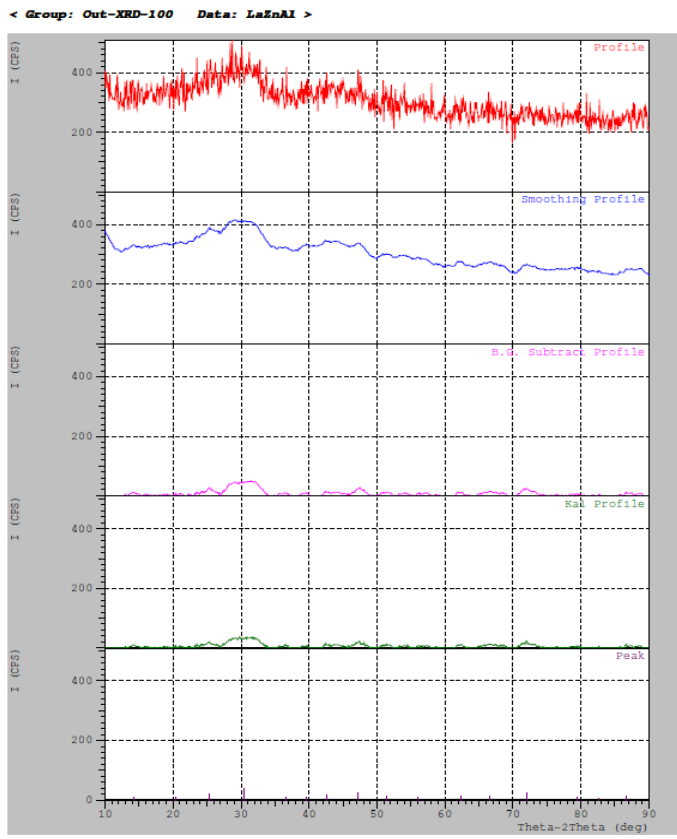

Fig. 3. XRD for LZA powder annealed at $450^{\circ} \mathrm{C}$

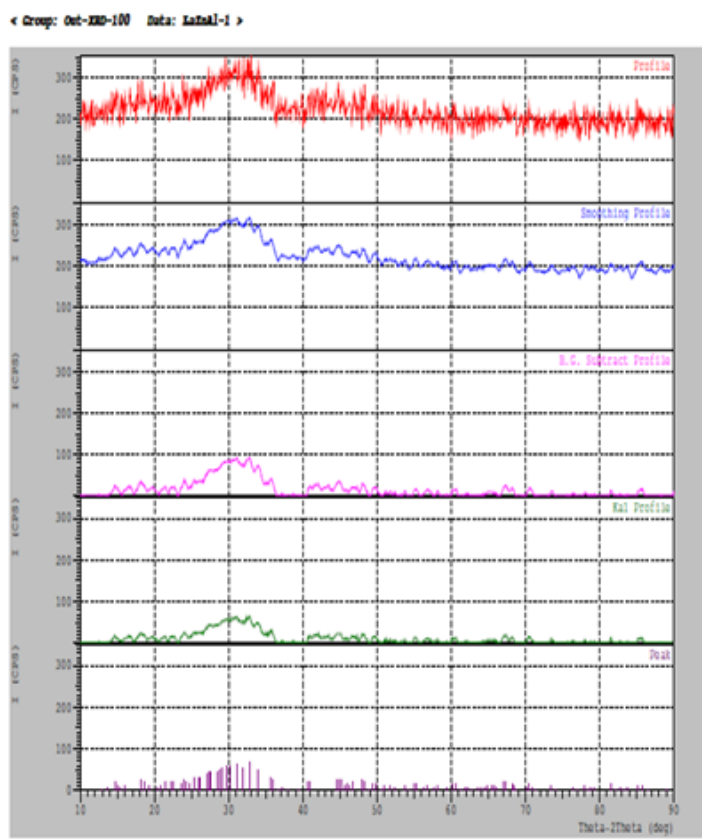

Fig. 4. XRD for LZA powder annealed at $750^{\circ} \mathrm{C}$ fig.3.From the SEM (fig.4), it is confirmed that smooth and uniform patterns are associated with fine grain $80 \mathrm{~nm}$ and $114.02 \mathrm{~nm}$ ) for powder form of lanthanum zinc aluminate which are annealed at $750^{\circ} \mathrm{C}$ 


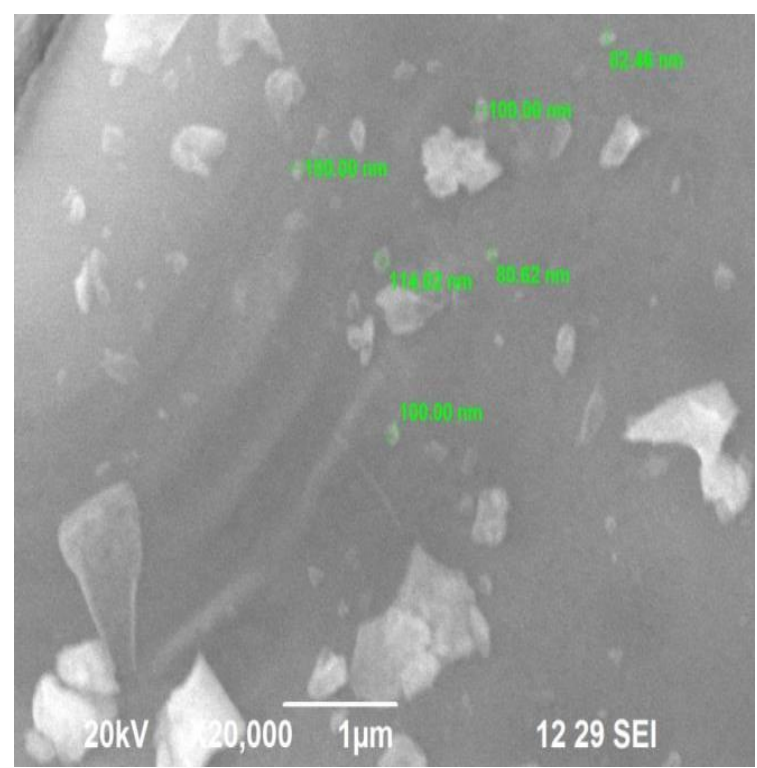

Fig. 6. SEM image for lanthanum zinc aluminate powder annealed at $750^{\circ} \mathrm{C}$

\section{CONCLUSION}

The lanthanum zinc aluminate powder is successfully extracted by using the sol gel method It was observed that the powder was amorphous when it was sintered at $450^{\circ} \mathrm{C}$ and Nano form when it was sintered at $750^{\circ} \mathrm{C}$

\section{REFERENCES}

1. Alejandro Hernández, Rossette Zdzislaw Mazur C, Alain Demeulenaere, J.A.Roque Lopez Hernández "The effect of start-up cycle in ceramic coating used as thermal barrier for a gas turbine bucket," Applied Thermal Engineering, Vol 29, pp 3056-3065(2009)

2. L. Wang, Y. Wang, X.G. Sun, J.Q. He, Z.Y. Pan, C.H. Wang, "A novel structure design towards extremely low thermal conductivity for thermal barrier coatings - Experimental and mathematical study, Materials and Design", pp505 -517 (2012)

3. Lisa Pin, Florence Ansart, Jean-Pierre Bonino, Yannick Le Maoult, Vanessa Vidal, Philippe Lours, "Processing, repairing and cyclic oxidation behavior of sol-gel thermal barrier coatings", Surface and Coatings Technology, Vol. 206, pp 1609 . 1614 (2011)

4. L. Wang, Y. Wang, X.G. Sun, J.Q. He, Z.Y. Pan, Y. Zhou, P.L. Wu, "Influence of pores on the thermal insulation behavior of thermal barrier coatings prepared by atmospheric plasma spray", Materials and Design, Vol.32, pp 36-47 (2011)

5. Shen Wei, Wang Fu-chi , Fan Qun-Bo, Ma Zhuang, "Effects of defects on the effective thermal conductivity of thermal barrier coatings", Applied Mathematical Modelling, Vol.36, pp 1995-2002 (2012)

6. Lorenzo Malavasi, Maria Cristina Mozzatib, Stefano Polizzi, Carlo Bruno Azzoni and Giorgio Flor, "Nanosized Sodium-Doped Lanthanum Manganites: Role of the Synthetic Route on their Physical Properties" Chemistry of Materials, Vol.15, pp (2003)

7. Rodica Rogojan, Ecaterina Andronescu, Cristina, Ghiţulică and Bogdan Stefan Vasile, "Synthesis and Characterization of Alumina Nano-Powder Obtained By Sol-Gel Method", UPB Scientific Bulletin, Series B: Chemistry and Materials Science,Vol.73, pp $67-$ 76 (2011)

\section{AUTHORS PROFILE}

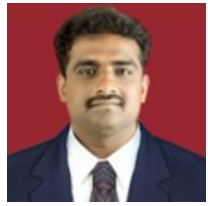

Dr. G. Kalusuraman is currently working as Associate Professor in the Department of Mechanical Engineering, Kalasalingam Academy of Research and Education, Anand nagar, Krishnankoil-626126,India $\mathrm{He}$ has 10 years teaching as well as research experience. He is a reviewer for two reputed journals $\mathrm{He}$ is a Member of Indian Society for Technical

Education. His area of interests are polymer composite, materials characterization, tribology.

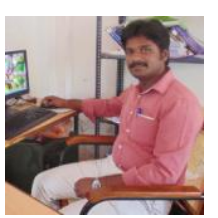

film Technology.
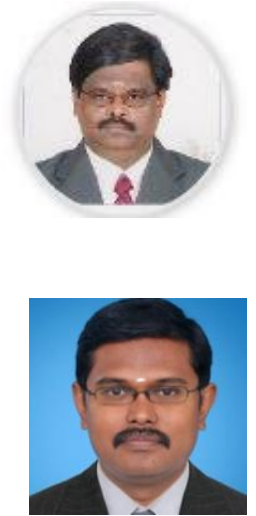

Dr. I. Siva is currently working as Professor in the Department of Mechanical Engineering, Kalasalingam Academy of Research and Education, Anand nagar, Krishnankoil-626126,India He has 15 years teaching as well as research experience. He is a reviewer more than 10 reputed journals $\mathrm{He}$ is a Member of Indian Society for Technical Education .His area of interests are polymer composite, materials characterization, tribology..
Dr. N. Sankara Subramanian is currently working as Professor in the Department of Physics, Thiagarajar College of Engineering, Madurai, India. He has 20 years teaching as well as research experience. . His area of interests are thin film technology .TBC

Dr. K. Balamurugan is currently working as rofessor in the Department of Mechanical Engineering, He has 10 years teaching as well as research experience. $\mathrm{He}$ is a reviewer for more than five reputed journals $\mathrm{He}$ i a Member of Indian Society for Technical Education. His area of interests are metal matrix composites, Thin 